\section{Difference between SB4 and reference etanercept in the hepatobiliary disorders not considered to be caused by SB4: response to letter by Scheinberg and Azevedo}

We thank Dr Sheinberg and colleagues' ${ }^{1}$ for raising the issue of hepatobiliary disorders mentioned in the European Public Assessment Report (EPAR) but not included in the 24-week report. ${ }^{2}$ This was due to the following reasons. First, the general safety reporting scheme was based on common adverse events ( $\geq 2 \%$ among reported adverse events, seen in table 2 of the paper), and overall major safety indices such as comparison of total treatment-emergent adverse events and serious adverse events. The groups of adverse events were those that were usually expected (or considered to be expected) to occur with etanercept use, such as serious infections, malignancies or injection site reactions. All of these were discussed in the 24-week paper. The imbalance of system organ class (SOC) hepatobiliary disorders found in the SB4 treatment group did not fit into any of these categories, as each distinct hepatobiliary event (such as bile duct stone, etc.) did not occur frequently enough to be $\geq 2 \%$, and also did not fit into the categories of serious infections, malignancies or injection site reactions. Second, the distribution of the adverse events from SOC hepatobiliary disorders was not clinically homogenous and was considered a mixture of two distinct areas of drug safety: either the potential for increased drug-related hepatocellular toxicity, or the propensity for increased risk for bile stones; so that reporting the 11 patients as a whole would have been misleading. When considering each area, among the 11 patients identified, only 3 patients purely belonged to the hepatocellular category. This was not considered to be a substantial difference, and as also seen in table 2, from the 24-week report, the incidence of alanine transaminase and asparate transaminase increases reported as an adverse event was comparable between the SB4 and reference etanercept (ETN) treatment groups ( $5.0 \%$ vs $4.7 \%$ and $2.3 \%$ vs $2.7 \%$, respectively). Of the remaining eight patients who had biliary events, two were found incidentally to have asymptomatic gallstones, after sonographic evaluation ordered for elevated liver enzymes. Therefore, the numerical imbalance is smaller than initially thought. Third, these patients usually had a biliary risk factor at baseline, such as older age, obesity, prior history of gallstones, medications or comorbidities, including cardiovascular risk/disease. ${ }^{3-5}$ When systematically analysed at the whole population level by baseline medical history and concomitant medications, there was a modest but generally higher trend of these biliary risk factors in the SB4 treatment group compared with the ETN treatment group (table 1), and this trend was considered to explain the substantial proportion of biliary risk of the SB4 population. Therefore, it was considered that the higher occurrence of biliary events was likely to be due to chance rather than to true SB4 causality, this was commented on in the EPAR.

As the 11 patients were heterogeneous in terms of safety classification, and the strength of causality for increased biliary risk by SB4 was questionable, it was felt inappropriate for us to discuss the imbalance of the SOC hepatobiliary disorders in the 24-week paper. It is to be noted that no additional hepatic or biliary risk was found beyond what was described in the EPAR, up to the end of the 100-week extension study. It is our opinion that extra surveillance for gallstones when treating patients with SB4 does not seem to be necessary, although the sponsor will monitor for this.

We hope that this will reassure Dr Scheinberg and colleagues for the safety of SB4, as well as to help maintain his enthusiasm on biosimilars.
Table 1 Summary of baseline imbalances of biliary risk factors in the total study population

\begin{tabular}{ll}
\hline Biliary risk factor & Summary results* \\
Age & Age $\geq 40$ years is 2.1\% more prevalent in SB4 over ETN \\
Sex & Female sex is 2.3\% more prevalent in ETN over SB4 \\
BMI & SB4 has more obese patientst than ETN (27.8\% vs 21.5\%) \\
Hypertension & SB4 12.6\% higher prevalence over ETN \\
Diabetes & SB4 $16.9 \%$ higher prevalence over ETN \\
Dyslipidaemia & SB4 24.2\% higher prevalence over ETN \\
$\begin{array}{l}\text { Coronary artery } \\
\text { disease }\end{array}$ & SB4 35.9\% higher prevalence over ETN \\
Hypothyroidism & ETN 22.2\% higher prevalence over SB4 \\
$\begin{array}{l}\text { Prior bile stone } \\
\text { history }\end{array}$ & ETN $11.7 \%$ higher prevalence over SB4 \\
Corticosteroid use & ETN and SB4 are almost similar (165 vs 168 patients) \\
Thiazide use & SB4 58.9\% higher use over ETN \\
\hline
\end{tabular}

* "over" means risk ratio of patients (eg, SB4: ETN patient incidence ratio or vice versa). tDefined as BMI $\geq 30 \mathrm{~kg} / \mathrm{m}^{2}$

$\mathrm{BMI}$, body mass index; ETN, etanercept.

\section{Paul Emery, ${ }^{1,2}$ Jiři Vencovský, ${ }^{3}$ Jeehoon Ghil, ${ }^{4}$ Soo Yeon Cheong, ${ }^{4}$} Young Hee Rho ${ }^{4}$

${ }^{1}$ Leeds Institute of Rheumatic and Musculoskeletal Medicine, University of Leeds, Leeds, UK

${ }^{2}$ NIHR Leeds Musculoskeletal Biomedical Research Unit, Leeds Teaching Hospitals NHS Trust, Leeds, UK

${ }^{3}$ Institute of Rheumatology, Prague, Czech Republic

${ }^{4}$ Samsung Bioepis Co., Ltd., Incheon, Republic of Korea

Correspondence to Professor Paul Emery, Leeds Institute of Rheumatic and Musculoskeletal Medicine, University of Leeds, Chapel Allerton Hospital, Chapeltown Road, Leeds LS7 4SA, UK; p.emery@leeds.ac.uk

Competing interests None declared.

Provenance and peer review Commissioned; internally peer reviewed.

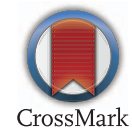

To cite Emery P, Vencovský J, Ghil J, et al. Ann Rheum Dis 2016;75:e65.

Accepted 20 July 2016

Published Online First 8 August 2016

\section{(P) Linked}

http://dx.doi.org/10.1136/annrheumdis-2016-210101

Ann Rheum Dis 2016;75:e65. doi:10.1136/annrheumdis-2016-210127

\section{REFERENCES}

1 Scheinberg M, Azevedo V. Difference between Enbrel and Benepali treatment groups in the 'hepatobiliary disorders'. Ann Rheum Dis 2016;75:e64.

2 Emery P, Vencovský J, Sylwestrzak A, et al. A phase III randomised, double-blind, parallel-group study comparing SB4 with etanercept reference product in patients with active rheumatoid arthritis despite methotrexate therapy. Ann Rheum Dis 2015; Published Online First 6 July 2015.

3 Laukkarinen J, Sand J, Autio V, et al. Bile duct stone procedures are more frequent in patients with hypothyroidism. A large, registry-based, cohort study in Finland. Scand J Gastroenterol 2010;45:70-4.

4 Méndez-Sánchez N, Bahena-Aponte J, Chávez-Tapia NC, et al. Strong association between gallstones and cardiovascular disease. Am J Gastroenterol 2005;100: 827-30.

5 Stinton LM, Shaffer EA. Epidemiology of gallbladder disease: cholelithiasis and cancer. Gut Liver 2012:6:172-87. 